\title{
O PAPEL DA TRADUÇÃO NA PESQUISA CIENTÍFICA BRASILEIRA: PRIMEIROS MOVIMENTOS ${ }^{1}$
}

\author{
Cristina Carneiro Rodrigues
}

John Milton (2001: 20) finaliza a introdução da edição especial da Crop sobre A História da Tradução no Brasil dizendo "esperar que o volume desperte a atenção e o interesse por essas florestas, talvez selvas, de pesquisa ainda virgens”. Da época da publicação do trabalho até hoje, a situação mudou e muito se tem escrito sobre a história da tradução no Brasil, mas ainda não o suficiente para afirmar que a linha esteja consolidada. ${ }^{2}$ O enfoque primordial dos estudos neste início de século foi a história da tradução literária no Brasil, mas a situação parece estar se modificando, com diversificação de enfoques. ${ }^{3}$

A pesquisa que vem sendo desenvolvida indica que a história da tradução é importante, em primeiro lugar, para informar como a tradução se insere na história social de um povo. É também relevante para a formação de tradutores, para que os alunos não concebam sua tarefa como um ato mecânico, pontual e inconsequente de passar textos para outras línguas. A abordagem histórica é fundamental para perceberem a dimensão política da tradução, para observarem as diferentes maneiras como a tradução pode se inserir na construção da cultura de um povo, para entenderem que a prática é antiga, assim como a reflexão sobre essa prática. Seu estudo revela que a tradução tem sido encarada por dois

\footnotetext{
${ }^{1}$ Versão preliminar deste trabalho foi apresentada na mesa-redonda intitulada "A pesquisa historiográfica sobre a tradução: teoria, metodologia e estudos de caso”, no XX Encontro Nacional de Tradutores e IV Encontro Internacional de Tradutores, que ocorreu em Ouro Preto, de 07 a 10 de setembro de 2009.

${ }^{2}$ Há apenas um grupo cadastrado no CNPq, liderado por Marie Helene Catherine Torres e Mauri Furlan, da UFSC, que se dedica à história da tradução no Brasil. O Grupo denomina-se "História da Tradução", enquadra-se na linha de pesquisa "História da Literatura Traduzida" e tem como objetivo estudar o papel da literatura traduzida no sistema literário brasileiro, fundamentando-se nos estudos descritivos da tradução e na obra de Berman. Há também algumas iniciativas de pesquisadores que buscam mapear certos temas. Mesmo correndo o risco de ser criticada por deixar de lado pesquisas relevantes, destaco os projetos de John Milton (2002), Lia Wyler (2003), Marcia Martins (2004) que traçam percursos abrangentes dessa história.

${ }^{3}$ As comunicações propostas na subárea Historiografia do X Encontro Nacional de Tradutores e IV Encontro Internacional de Tradutores, ocorrido de 07 a 10 de setembro de 2009, apontam para a abertura de um promissor leque de direcionamentos: de 18 comunicações, apenas seis tinham enfoque exclusivamente literário. A diversificação de enfoques parece ser tendência contemporânea nos estudos da história da tradução. Evidência disso é a Introdução de A tradução cultural, em que Perter Burke e R. Po-Chia Hsia (2009: 9) informam que uma das metas do livro é “complementar o trabalho existente sobre a História da Tradução” e compensar lacunas: "enquanto obras anteriores privilegiaram a tradução literária, este volume trata da não-ficção, da transmissão de informações e conhecimentos de uma língua para outra”.
} 
ângulos: por um lado, vista como uma ameaça a uma cultura, porque corromperia os padrões nacionais, seria um "veículo de aculturação” (Wyler, 2003: 25); por outro lado, considerada como um meio de uma cultura, um povo, poder transformar-se com a contribuição do Outro.

O estudo da história da tradução informa, ainda, que nem sempre a contribuição do Outro se dá pela tradução. É esse o enfoque dado à história da literatura brasileira. José Paulo Paes (1990: 10) afirma que "a influência das traduções sobre a literatura criativa brasileira é limitada", pois muitos de "nossos poetas, romancistas e teatrólogos, por conhecerem idiomas estrangeiros, puderam travar conhecimento com os autores de quem iriam eventualmente sofrer influência antes de eles haverem sido vertidos para o português”. No entanto, a tradução de literatura como “um exercício de recriação” teve um papel significativo, como aponta Pagano (2001: 191), na medida em que muitos escritores brasileiros praticaram a tradução literária.

Mas, se temos já um conhecimento razoável da história da tradução literária no Brasil, pouco se sabe sobre o papel que a tradução de textos não ficcionais teve na construção dos saberes nacionais. É amplamente divulgado que a primeira tradução publicada no Brasil pela Impressão Régia, depois de três séculos de interdição da imprensa no Brasil, foi Elementos de geometria, "para uso nas várias instituições de ciência e de ensino superior criadas a partir de 1808” (Wyler, 2003: 79). Mas a história não informa qual foi o alcance das traduções no desenvolvimento da ciência no Brasil, quem foram os tradutores, o que foi traduzido.

Para Pedro Calmon (1959: 2345), não se pode falar em um "movimento coordenado e universitário de investigação científica” antes das Faculdades de Filosofia (anos 1930) e do Conselho Nacional de Pesquisa (1952). No período anterior, as conquistas teriam ficado a cargo de "sábios e instituições isoladas". Isso indica que as primeiras traduções feitas no Brasil no século XIX tiveram papel pouco significativo como propulsoras da pesquisa brasileira.

A partir desses dados, pode-se indagar se em algum momento a tradução teve papel na construção da ciência brasileira e se as universidades realmente marcaram o início da pesquisa no Brasil. O objetivo deste trabalho é buscar caminhos para responder a essas questões. 
O primeiro passo é verificar quando se instituem as universidades brasileiras e qual é o cenário editorial da época. No início do século XX começa a haver uma pressão da expansão industrial e urbana, levando à fundação das Faculdades de Filosofia, e das Universidades. A Universidade do Rio de Janeiro foi criada em 1920, com a fusão de três escolas superiores, Medicina, Politécnica e Direito, mas, de acordo com Calmon (1959), sua coesão só ocorre em 1937, quando passa a se denominar Universidade do Brasil. A Universidade de Minas Gerais foi criada em 1927, a de São Paulo em 1934. ${ }^{4}$ Durante o governo Dutra ocorre a federalização das universidades, mas a de Minas Gerais e a de São Paulo continuam estaduais. Depois da federalização é que se estabelecem as Universidades do Rio Grande do Sul, do Distrito Federal, do Ceará e do Pará. Assim, com exceção da Universidade de Minas Gerais, os centros universitários instituem-se a partir dos anos 1930 época em que chamamos amplamente de Era Vargas. ${ }^{5}$

Para Vargas, saúde e educação eram os pontos chave para construir a nação com homens, esgotos e livros, tanto que cria, logo depois de assumir o governo em 1930, o Ministério da Educação e Saúde Pública - instruir caminhava junto com higienizar. Em relação ao ensino, busca-se um sistema de educação orgânico e nacional, que culmina com o Estatuto das Universidades Brasileiras e a reforma do ensino secundário e do profissionalizante. As medidas governamentais e a crise mundial de 1929 geraram a necessidade de publicação local de livros, tanto com fins pedagógicos quanto fruitivos, o que motiva a expansão do mercado editorial. Os trabalhos de Sônia Maria de Amorim (1999), de Elisabeth Rochadel Torresini (1999), de Adriana Pagano (2001) e de Milton (2002) registram o percurso dessa expansão enfocando especialmente a publicação de obras de ficção. Os autores evidenciam que essa é a época do boom editorial brasileiro, que tanto foi um boom da tradução, quanto da publicação de coleções (Pagano, 2001).

Enquanto temos razoável conhecimento sobre a tradução literária no período, a bibliografia sobre publicação de livros pedagógicos e destinados à pesquisa, no entanto, é escassa e eventual. Das coleções de textos não literários lançadas no período, uma das mais

\footnotetext{
${ }^{4}$ A Faculdade de Medicina de São Paulo havia sido fundada em 1913, mas a grande inovação propulsora de pesquisa na área médica ocorreu em 1924, quando as cadeiras básicas passam a ser exercidas em tempo integral (Reis, 1979-1980: 17).

${ }^{5}$ Getúlio Vargas assume o governo em 1930, recorre à decretação do Estado Novo em novembro de 1937 e fica no poder até fim de 1945. Entre janeiro de 1946 e janeiro de 1951 o presidente do Brasil foi Eurico Gaspar Dutra, mas Vargas reassume a presidência sem ter deixado permanecer como figura central na política até sua morte, em 1954.
} 
importantes e que tem sido objeto de historiadores que examinam o lugar dos impressos na vida política nacional foi a Biblioteca Pedagógica Brasileira, projetada pelo intelectual e educador Fernando de Azevedo e empreendimento da Companhia Editora Nacional, dirigida por Octalles Marcondes Ferreira. A coleção foi idealizada tanto com intuito de impulsionar o conhecimento quanto de ampliar o público de leitores. Cinco subséries faziam parte dessa Biblioteca: Literatura Infantil; Livros Didáticos; Atualidades Pedagógicas; Iniciação Científica; e Brasiliana. As quatro últimas publicaram produção nacional e traduções; na subsérie Literatura Infantil, destinada a estudantes de escolas primárias, foram publicadas obras de Monteiro Lobato, mas como não tive acesso às obras, não é possível informar se traduções também_eram editadas na subsérie.

A segunda subsérie da Biblioteca Pedagógica Brasileira, Livros Didáticos, é composta por livros de texto com os conteúdos adequados aos diferentes níveis de ensino, especialmente os indicados para o secundário e o ginasial. A terceira subsérie, Atualidades Pedagógicas, ${ }^{6}$ era destinada a normalistas e acadêmicos dos cursos de Pedagogia e Didática. A coleção tinha como objetivo apoiar a formação de educadores, não fornecer fonte de pesquisa em Educação. Os volumes traduzidos a que tive acesso tinham os nomes dos tradutores nas capas, todos autoridades, como Godofredo Rangel, Anísio Teixeira e o diretor da série, Luiz Damasco Penna.

A quarta subsérie, Iniciação Científica, traz guias, vocabulários, glossários, sobre sociologia, psicologia, zoologia etc., mas são livros introdutórios, não destinados a pesquisadores formados. Também nessa série constam os nomes dos tradutores nas capas, assim como na lista dos volumes publicados. Nela verifica-se que Menotti del Picchia traduziu a biografia de Marx, que os Drs. Durval Marcondes e Barbosa Correia traduziram as 5 lições de psicanálise, de Freud, que Cecília Meirelles traduziu Os mitos hitleristas, de François Perroux.

\footnotetext{
${ }^{6}$ Luiz Damasco Penna, diretor da série, Delegado Regional de ensino em Santos e tradutor de vários dos volumes publicados nessa coleção, informa que na subsérie se editam obras clássicas e que a "atualidade está mais na força inspiradora e propulsora de ideias que na exclusiva contemporaneidade. Atualidade pretende ser, assim, também, e principalmente, efetividade" (1952, s/p).
} 
A quinta subsérie, a Brasiliana, ${ }^{7}$ é considerada por Dutra (2006, p. 301) como “o maior empreendimento editorial destinado a reunir um conhecimento sistemático sobre o Brasil, ainda hoje sem equivalente na história da edição do país”. Fernando de Azevedo a dirigiu de 1931 a 1957 e Américo Jacobina Lacombe o substituiu. O projeto da Brasiliana envolvia a publicação de ensaios sobre o Brasil e estudos de problemas nacionais. Seu conteúdo e objetivo são explicitados no texto da orelha de algumas das obras publicadas na primeira edição. $^{8}$ Nesse texto informa-se que os estudiosos sobre o Brasil apontavam a carência de obras informativas e de consulta, que estariam esgotadas, dispersas, ou ainda não traduzidas; o objetivo da Coleção Brasiliana seria reunir, em uma única série, os livros clássicos e os novos trabalhos sobre o Brasil e seus problemas. Salienta-se que o "material de valor documentário” publicado seria fundamental para o desenvolvimento de estudos sobre o Brasil. Entretanto, o fato de a série ter como objetivo impulsionar a pesquisa, não significa necessariamente que esse objetivo foi atingido.

Entre 1931 e 1954 foram publicados 277 títulos na subsérie, 42 deles traduções do inglês, francês ou alemão. A maior parte dessas obras é classificada como relatos de viajantes como Auguste de Saint-Hilaire, Jean Charles Marie Expilly, Louis Agassiz e Elizabeth Cabot Cary Agassiz, Johann Baptist von Spix e Karl Friedrich Philipp von Martius, George Gardner, André Thevet. Entre os intelectuais, professores e pesquisadores que assinam as traduções encontramos Afonso Taunay, Américo Jacobina Lacombe, Carlos

\footnotetext{
7 "Brasiliana" é denominação para qualquer coleção de textos ou imagens que tenham como tema aspectos da vida ou da cultura brasileira. De acordo com Pontes (1989), são três as mais importantes “Coleções Brasiliana” editadas na Era Vargas: a Brasiliana, criada em 1931 pela Companhia Editora Nacional; a Documentos Brasileiros, lançada em 1936 pela Editora José Olympio; e a Biblioteca Histórica Brasileira, produzida a partir de 1940 pela Livraria Martins Editora. Todas tinham como objetivo "desvendar, mapear, estudar e diagnosticar a realidade brasileira” (Pontes, 1989: 359).

${ }^{8}$ A parte do texto em que se explicitam os objetivos é a seguinte:

“A 5.a série, que figura na B. P. B. [Biblioteca Pedagógica Brasileira] com o título de "Brasiliana”, é a mais vasta e completa coleção e sistematização que se tentou, até hoje, de estudos brasileiros. Esta série compõe-se de ensaios sobre a formação histórica e social do Brasil; de estudos de figuras nacionais e de problemas brasileiros (históricos, geográficos, etnológicos, políticos, econômicos, etc.); de reedições de obras raras e de notório interesse e de traduções de obras estrangeiras sobre assuntos brasileiros. Todos os que se dedicavam a estudos sobre o Brasil eram unânimes em reconhecer as grandes dificuldades criadas, para as suas investigações, pela raridade de obras de informações e de consultas, muitas já esgotadas, outras por traduzir, quase todas dispersas. A C. E. N. [Companhia Editora Nacional] propôs-se a coligir estas obras, reeditá-las ou traduzi-las e a promover e estimular a produção deste gênero, reunindo, em uma série, não só os livros clássicos e os novos trabalhos sobre o Brasil e seus problemas, como todo o material de valor documentário. A aceitação pública que granjeou desde logo a "Brasiliana” veio provar a utilidade e o alcance desta iniciativa de coordenação e de sistematização de estudos e de pesquisas sobre os assuntos e problemas nacionais, encarados sob todos os aspectos.”
} 
Lacerda, Edgar Süssekind de Mendonça, Gastão Penalva, Jamil Almansur Haddad, Luiz da Camara Cascudo, Sérgio Buarque de Hollanda e Sérgio Milliet, muitos deles com seus nomes nas capas dos volumes.

Ainda que vários autores, como Pontes (1989: 393), salientem que os relatos de viagem seriam fonte obrigatória de consulta para quem quisesse interpretar o Brasil, pois documentariam nossa história social e política, além de oferecerem conhecimento sobre flora, fauna, costumes, geografia, geologia, política, seria necessário comprovar o uso efetivo das traduções como referência.

Um primeiro movimento foi buscar nos próprios livros da Coleção Brasiliana essas referências às traduções. O problema enfrentado é que não havia padronização para sua apresentação, e a maior parte dos livros sequer fornece bibliografia. Ainda assim, foram encontradas remissões às obras traduzidas da Coleção Brasiliana em livros escritos por autores brasileiros. Os historiadores Pedro Calmon, Afonso Taunay, Pe. Serafim Leite, o engenheiro Pandiá Calógeras, o zoólogo Cândido de Mello-Leitão, o etnólogo Estêvão Pinto remetem a algumas dessas traduções. Pedro Calmon é o mais preciso, pois suas notas trazem referência completa às obras consultadas, incluindo os nomes dos tradutores. Outros tradutores da época também informam usar obras traduzidas publicadas em obras de outras “Coleções Brasilianas”. É o caso da obra Da medicina brasileira, de Guilherme Piso (1948), em que o tradutor Alexandre Correia, em suas notas, faz referência à tradução da obra de Nieuhof, feita por Moacir N. Vasconcellos e anotada por José Honório Rodrigues (p. 329), à tradução da obra de Barleu feita por Claudio Brandão (p. 329), a Kahn em tradução de L. Mendonça de Barros (p.335), à “tradução e comentos magníficos” de Pirajá da Silva (p. 359), ao texto de Hermann Watjen em tradução de P. Uchôa Cavalcanti (p. 372), além de livros de autores nacionais publicados na Coleção Brasiliana. Mesmo autores estrangeiros publicados na época fazem referência a títulos publicados na Brasiliana - é o caso, por exemplo, de Alexander Marchant (1942), que cita Almeida Prado e Roberto Simonsen em seu livro sobre as relações econômicas de portugueses e índios na colonização do Brasil (1500-1580).

Esses dados indicam que os livros da Brasiliana foram fonte de consulta para muitos autores, mas não atestam se as traduções publicadas tiveram algum papel na construção da ciência brasileira, nem que a investigação científica no Brasil teria mesmo se iniciado com 
a fundação das Faculdades de Filosofia. Os livros História das ciências no Brasil (Ferri; Motoyama, 1979-1980) e Formação da comunidade científica no Brasil (Schwartzman, 1979) forneceram informações a esse respeito.

De acordo com Schwartzman (1979: 80), até o início da primeira República, a atividade científica no Brasil se caracterizava por sua “extrema precariedade", fato explicado pela desvalorização da atividade pelos setores sociais. A grande exceção é a microbiologia, que, por conta de questões de saúde pública, de necessidade de fabricação de soros e vacinas e de estudo de doenças parasitárias e infectuosas, desenvolveu-se em meados do século XIX. Mas mesmo nessa história da microbiologia no Brasil há referência à tradução: existiria, na época, uma “Escola Tropicalista Baiana” à qual estavam ligados importantes médicos (Reis, 1979-1980: 4). Entre os “pesquisadores de grande valor”, o autor registra Pirajá da Silva, tradutor de dois livros de von Martius publicados na Coleção Brasiliana. Das demais ciências, quase todas trazem a criação das faculdades como marco nas pesquisas. Segundo Schwartzman (1979), a fundação da Universidade de São Paulo acelera o processo de transformação que se insinuava na comunidade científica. Desse modo, apenas a partir dos anos 1930 começa a solidificar-se a ideia da vinculação entre ensino e pesquisa.

O histórico das várias ciências no Brasil é pontuado por referências a traduções. A história da Botânica narrada por Ferri (1979-1980) é subdividida em três fases. A primeira fase inicia-se com referências aos primeiros viajantes que estiveram no Brasil. São explicitamente mencionados: Hans Staden, em tradução de Loefgren de 1930 (Biblioteca de Cultura Nacional); Thevet, traduzido por Estevão Pinto e publicado na Coleção Brasiliana em 1944; a “excelente tradução” de Léry, feita por Sérgio Milliet em 1941 (p. 37) e publicada na Biblioteca Histórica Brasileira; a Historia Naturalis Brasiliae, de Marcgrave, “traduzida por Monsenhor D. José Procópio de Magalhães e publicada em 1942 [Imprensa Oficial]” (p. 39); a tradução da obra de Guilherme Piso, feita por Alexandre Correia e editada pela Companhia Editora Nacional em 1948 (p. 41), além de outros autores que escreveram em português até o século XVIII. A segunda fase da Botânica ocorre no século XIX com o trabalho dos naturalistas que visitaram o Brasil no período. No entanto, suas pesquisas não chegaram a despertar, na época, o interesse científico dos brasileiros pela botânica. Ao historiar essa fase, Ferri destaca a obra de Maximiliano, traduzida por Edgar 
Süssekind de Mendonça e Poppe de Figueiredo, publicada na Coleção Brasiliana em 1940 (p. 46); a de Saint-Hilaire, “em excelente tradução de Rubens Borba de Moraes”, publicada em 1945 na Biblioteca Histórica Brasileira (p. 48), mas lista também, na bibliografia, todas as demais traduções das viagens de Saint-Hilaire publicadas na Coleção Brasiliana. Ferri menciona também a obra de Carl Friedrich von Martius e Johann Baptist von Spix, cujos excertos foram “publicados, em 1916, por Manuel A. Pirajá da Silva e Paulo Wolf” (p. 49), obra republicada na Coleção Brasiliana em $1938 .{ }^{9}$

Todas as referências de Ferri demonstram inequivocamente que a pesquisa em Botânica se beneficiou com as traduções, especialmente com as obras dos naturalistas do século XIX - não apenas com as traduções das coleções Brasilianas da Era Vargas, como também com as publicações mais recentes. Para Ferri (1979-1980: 82), os relatos de viagens “trazem uma contribuição inestimável ao conhecimento de nossa flora, em seus vários aspectos. Tais publicações são ainda hoje de grande valor e por isso vêm sendo constantemente editadas no Brasil, porque o interesse que elas despertam é imorredouro". Mas assinala ainda a criação da Universidade de São Paulo como o marco nos estudos botânicos nacionais. ${ }^{10}$ Ferri não apenas menciona as traduções em sua bibliografia, como também assinala os nomes dos tradutores que se debruçaram sobre os textos a que se refere. $^{11}$

Na história das Geociências no Brasil também encontram-se referências às traduções, especialmente às dos chamados “viajantes-naturalistas”. Nesse caso, os autores não mencionam no corpo do texto os tradutores das obras a que se referem, nem trazem na bibliografia sua relação. A única referência direta que os autores fazem é à "excelente edição brasileira de Marcgrave (1942), tradução de Monsenhor José Procópio de

\footnotetext{
${ }^{9}$ Ferri (1979-1980) refere-se também a outras traduções mais recentes, especialmente à editada pela Itatiaia em co-edição com a EDUSP, mas essas obras estão fora do escopo deste trabalho.

${ }^{10}$ Outro marco mencionado por Ferri (1979-1980, p. 83) é “a criação da Editora da Universidade de São Paulo [1963], com publicações de textos de Botânica, em diversos setores, traduzidos e de autores nacionais”.

${ }^{11}$ Nota-se a preocupação de Ferri (1979-1980), assim como de outros autores, com a menção dos tradutores no corpo do texto ou nas referências. Esse cuidado demonstrado em publicações até os anos 1980 suscita uma questão: quando e em que setores se dá a desvalorização da tradução no Brasil? Os muitos comentários elogiando traduções da época leva-nos também a questionar a afirmação de Hallewell (2005) de que o padrão das traduções antes de 1940 ser baixo. Para o autor eram escassos os tradutores competentes e as editoras pouco se preocupavam com as traduções, pagando mal os tradutores. Isso teria estabelecido "uma tradição, que perdura até hoje, de que a tradução é um trabalho subalterno e mal remunerado” (p. 402); nada posso dizer a respeito da remuneração dos tradutores na época, mas os historiadores da ciência aqui citados mostram que não podemos desqualificar genericamente as traduções de antes da década de 1940.
} 
Magalhães”, anotada pelo “climatologista brasileiro Salomão Serebrenick” (Ab’Sáber; Christofoletti, 1979-1980: 127).

A Etnologia brasileira é historiada em três períodos: o pré-científico, o dos “naturalistas viajantes” e o moderno, que tomou “extraordinário impulso a partir da década dos trinta” (Schaden, 1979-1980: 241, 246). Também nessa área os relatos de viajantes são importantes, destacando-se os alemães, como Maximiliano e Martius, e os franceses, como Saint-Hilaire e Coudreau.

O histórico da Biologia já se inicia pela afirmação de que, “antes da fundação das Faculdades de Filosofia, os problemas zoológicos eram estudados em institutos de Medicina Experimental e nos Museus” (Narchi, 1979-1980: 91). O artigo informa, em seu final, que "o advento da F.F.C.L. [Faculdade de Filosofia, Ciências e Letras] da USP trouxe um impulso novo para os estudos no campo da Zoologia” (p. 116). Como não traz bibliografia, não há como avaliar o impacto das traduções nessa história, apenas o da Universidade.

Para Hönig e Gomide (1979-1980), a Matemática antes de 1934 é pré-histórica. Com a criação da Faculdade de Filosofia Ciências e Letras da USP (1934), da Escola de Ciências do Distrito Federal (1935) e da Faculdade Nacional de Filosofia da Universidade do Brasil (1939), “começa um período novo na História da Matemática no Brasil” (p. 45). Nessas instituições “constituem-se os primeiros núcleos de pesquisa e começa uma evolução no ensino da Matemática” (p. 45). Não há menção à tradução. De acordo com Miorin, não há livros sobre Matemática na Coleção Brasiliana. Há, entretanto, várias traduções publicadas nas subséries Didáticos e Atualidades Pedagógicas. ${ }^{12}$

Ainda que a trajetória da filosofia no Brasil seja narrada com a remissão a pesquisadores brasileiros, encontra-se nela a menção a Emmanoel Carneiro Leão, que "traduziu textos fundamentais de Heidegger, comentou sua obra em ensaios e publicações periódicas. [...] Outros autores de obras de idêntica inspiração são Gerd Bornheim, Ernildo Stein e Eudoro de Souza” (Paim, 1979-1980: 27-28). Informa-se também que, devido ao fato de a Filosofia das Ciências ter-se disseminado na Universidade, houve significativo

\footnotetext{
${ }^{12}$ Na subsérie Didáticos foram publicados vários títulos traduzidos. Na subsérie Atualidades Pedagógicas, Miorim (2006: 10) identifica apenas um livro traduzido, La pédagogie des mathématiques, de André Fouché, “com tradução de Luís Magalhães de Araújo e Antônio Sales Campos, professores do Colégio Rio Branco de São Paulo. Essa publicação insere-se na nova política editorial proposta por Penna [diretor da série, na época], de valorização da produção de traduções, em que eram privilegiadas as obras de autores franceses”.
} 
movimento editorial, com a tradução dos "mais importantes textos clássicos (Wittgenstein, Popper, Russell, etc.)” (Paim, 1979-1980: 29).

De acordo com o historiador Iglésias (1979-1980: 280-281), que assina o capítulo “História no Brasil”, “os livros mais significativos da História atual [anos 1930 a 1960] não foram escritos por professores universitários, mas por gente cuja carreira se fez à margem da Universidade”: Oliveira Viana, Gilberto Freyre, Caio Prado Júnior, Raimundo Faoro, Celso Furtado e Virgínio Santa Rosa. Outros tiveram curta passagem pela Universidade, como Sérgio Buarque de Holanda, Vitor Nunes Leal e José Honório Rodrigues. Este, considerado o historiador de produção mais significativa dos anos 1950 a 1970, em resenha de Formação do Brasil contemporâneo, de Caio Prado Júnior, demonstra o uso que os historiadores podem fazer das traduções. Critica uma análise feita por Prado, afirmando que ela poderia ter sido feita "comparando-se especialmente os livros de viajantes que, no correr do século XIX, nos visitaram” (Rodrigues, 1970: 94), e remete a Koster, em tradução publicada na Coleção Brasiliana em 1942, a Martius, (obra editada pela Imprensa Nacional), a Gardner da Coleção Brasiliana, e a Saint-Hilaire da Biblioteca Histórica Brasileira, da Martins. No decorrer da resenha, recorre ao trabalho de outros viajantes, para obter dados mais confiáveis que os fornecidos por Prado: Agassiz, Kidder e Fletcher, Hartt e Saint-Hilaire da Coleção Brasiliana, e Johan Nieuhof, publicado na Biblioteca Histórica Brasileira, da Martins. Como esse artigo do historiador José Honório Rodrigues foi publicado pela primeira vez em 1943, o texto indica que as traduções dos anos 1930 e 1940 tiveram repercussão quase imediata na pesquisa historiográfica brasileira.

Da história das ciências no Brasil que delineei evidenciam-se dois pontos. Em primeiro lugar, que a investigação científica no Brasil se inicia, em quase todos os campos do saber, na Era Vargas, com o estabelecimento dos centros universitários e com a instituição do tempo integral para os docentes. O segundo ponto é que há uma maneira de verificar o papel da tradução na investigação científica brasileira: debruçar-se sobre os trabalhos dos intelectuais nacionais. O levantamento feito evidenciou que os pesquisadores que buscaram examinar a realidade brasileira contaram com as traduções - especialmente com as obras dos viajantes-naturalistas. Nesse sentido, elas atuaram como coadjuvantes na formação cultural brasileira. Não simples aculturação, mas transformação: de um Brasil 
rural, com acentuadas desigualdades sociais e altos índices de analfabetismo, para um Brasil urbano e industrializado.

Mas há ainda um outro aspecto a ser considerado: o fato de que os intelectuais brasileiros praticavam amplamente a tradução nos anos 1930 e 1940. Historiadores, médicos, filósofos, etnólogos, educadores traduziam as principais obras de suas áreas. Ao mesmo tempo em que produziam suas obras, disponibilizavam as dos pesquisadores que consideravam fundamentais para futuras pesquisas. Creio que a situação exemplar é a da Educação: Fernando de Azevedo, Anísio Teixeira e Lourenço Filho não apenas se empenharam na implantação da Educação Nova - escreveram sobre ela e traduziram os textos basilares da área. ${ }^{13}$

Vemos historiadores da tradução afirmarem que, nas histórias da literatura e na história da inteligência brasileira, pouco se fala das traduções; mas aqui mostrei que, na história das ciências, ela é bem notada. E mesmo que a tradução não tenha impulsionado diretamente a pesquisa em todas as áreas do conhecimento no Brasil, pelo menos permitiu a pesquisadores e a estudantes o acesso fácil e relativamente barato a importantes fontes de consulta.

Como o material pesquisado - as “Coleções Brasilianas” - tem a peculiaridade de trazer eminentemente traduções de textos de viajantes-naturalistas cujos estudos versaram por várias áreas do conhecimento, da Botânica às Geociências, passando pela Biologia, Etnologia e outras tantas, podemos avaliar seu papel na pesquisa e no ensino universitário. No ensino fundamental e médio, esse impacto ainda está por ser avaliado.

\section{Referências bibliográficas}

AB’SÁBER, Aziz Nacib; CHRISTOFOLETTI, Antônio. Geociências. In: FERRI, Mário Guimarães; MOTOYAMA, Shozo (Org.). História das ciências no Brasil. São Paulo: EPU: Ed. da USP, 1979-1980. p. 117-238. v. 2.

\footnotetext{
${ }^{13}$ Fernando de Azevedo, Anísio Teixeira e Lourenço Filho atuaram em frentes educacionais antes do início da Era Vargas, estando entre os signatários do Manifesto pela Educação Nova, de 1932. Um dos títulos da subsérie Atualidades Pedagógicas é Novos caminhos e novos fins: a nova política de educação, em que Fernando de Azevedo apresenta a Reforma da Escola Nova.
} 
AMORIM, Sônia Maria de. Em busca de um tempo perdido: edição de literatura traduzida pela Editora Globo (1930-1950). São Paulo: Edusp: Com-Arte; Porto Alegre: Editora da UFRGS, 1999.

BURKE, Perter; HSIA, R. Po-Chia (Org.). A tradução cultural nos primórdios da Europa Moderna. São Paulo: Ed. UNESP, 2009.

CALMON, Pedro. História do Brasil. Rio de Janeiro: José Olympio, 1959. v. 7.

DUTRA, Eliana de Freitas. A nação nos livros: a biblioteca ideal na coleção Brasiliana. In: ; MOLLIER, Jean-Yves (Org.). Política, nação e edição: o lugar dos impressos na construção da vida política. São Paulo: Annablume, 2006. p. 299-314.

FERRI, Mário Guimarães; MOTOYAMA, Shozo (Org.). História das ciências no Brasil. São Paulo: EPU: Ed. da USP, 1979-1980. p. 265-301. 2 v.

FERRI, Mário Guimarães. História da botância no Brasil. In: ; MOTOYAMA, Shozo (Org.). História das ciências no Brasil. São Paulo: EPU: Ed. da USP, 19791980. p. 33-88. v. 2.

IGLÉSIAS, Francisco. História no Brasil. In: FERRI, Mário Guimarães; MOTOYAMA, Shozo (Org.). História das ciências no Brasil. São Paulo: EPU: Ed. da USP, 19791980. p. 265-301. v. 1.

HALLEWELL, Lawrence. O livro no Brasil: sua história. Tradução Maria da Penha Villalobos, Lólio Lourenço de Oliveira e Geraldo Gerson de Souza. 2 ed. rev. e ampl. São Paulo: Ed. da USP, 2005.

HÖNIG, Chaim S.; GOMIDE, Elza F. Ciências Matemáticas. In: FERRI, Mário Guimarães; MOTOYAMA, Shozo (Org.). História das ciências no Brasil. São Paulo: EPU: Ed. da USP, 1979-1980. p. 35-60. v. 1.

MARCHANT, Alexander. Do Escambo à escravidão: as relações econômicas de portugueses e índios na colonização do Brasil (1500-1580). Tradução Carlos Lacerda. São Paulo: Ed. Nacional, 1943.

MARTINS, Marcia A. P. (Org.). Visões e identidades brasileiras de Shakespeare. Rio de Janeiro: Lucerna, 2004.

MILTON, John. Introduction. Crop, v. 6, p. 13-20, 2001.

O Clube do Livro e a tradução. Bauru, EDUSC, 2002.

MIORIM, Maria Angela. A Biblioteca Pedagógica Brasileira da Companhia Editora Nacional e o ensino de matemática: livros, autores e estratégias editoriais. Horizontes, v. 24, n. 1, p. 9-21, jan./jun., 2006. 
NARCHI, Walter. A Zoologia no Brasil. In: FERRI, Mário Guimarães; MOTOYAMA, Shozo (Org.). História das ciências no Brasil. São Paulo: EPU: Ed. da USP, 19791980. p. 89-116. v. 2.

PAES, José Paulo. A tradução literária no Brasil. In: Tradução: a ponte necessária. São Paulo: Ática, 1990. p. 9-31.

PAGANO, Adriana. "An item called books": translations and publishers' collections in the editorial booms in Argentina and Brazil from 1930 to 1950. Crop, v. 6, p. 171-194, 2001.

PAIM, Antônio. Trajetória da Filosofia no Brasil. In: FERRI, Mário Guimarães; MOTOYAMA, Shozo (Org.). História das ciências no Brasil. São Paulo: EPU: Ed. da USP, 1979-1980. p. 9-34. v. 1.

PENNA, Luiz Damasco. A Coleção Atualidades Pedagógicas. In: FOULIQUIE, Paul. As escolas novas. São Paulo: Ed. Nacional, 1952.

PISO, Guilherme. Da medicina brasileira. Tradução Professor Alexandre Correia. São Paulo: Ed. Nacional, 1948.

PONTES, Heloísa. Retratos do Brasil: editores, editoras e "Coleções Brasiliana” nas décadas de 30, 40 e 50. In: MICELI, Sergio. História das Ciências Sociais no Brasil. São Paulo: Revista dos Tribunais, 1989. p. 359-409. v. 1.

REIS, José. Microbiologia. In: FERRI, Mário Guimarães; MOTOYAMA, Shozo (Org.). História das ciências no Brasil. São Paulo: EPU: Ed. da USP, 1979-1980. p. 1-31. v. 2.

RODRIGUES, José Honório. Formação do Brasil contemporâneo. In: História e historiografia. Petrópolis: Vozes, 1970.

SHADEN, Egon. A etnologia no Brasil. In: FERRI, Mário Guimarães; MOTOYAMA, Shozo (Org.). História das ciências no Brasil. São Paulo: EPU: Ed. da USP, 19791980. p. 239-271. v. 2.

SCHWARTZMAN, Simon. Formação da comunidade científica no Brasil. Rio de Janeiro: FINEP: Ed. Nacional, 1979.

TORRESINI, Elisabeth Rochadel. Editora Globo: uma aventura editorial nos anos 30 e 40. São Paulo: Ed. da USP; Porto Alegre: Ed. da UFRGS, 1999.

WYLER, Lia. Línguas, poetas e bacharéis: uma crônica da tradução no Brasil. Rio de Janeiro: Rocco, 2003. 